\section{Isolated Metastasis of Left Seminal Vesicle due to Colon Adenocarcinoma: An Unusual Pattern of Metastasis}

Sir,

Mucinous adenocarcinoma is a subtype of colorectal cancer (CRC) that generally affects females and younger patients. ${ }^{1}$ Regional lymph nodes, liver and lungs are the most common metastatic sites of CRC. ${ }^{1-3}$

A 47-year male underwent an extended left hemicolectomy with the diagnosis of splenic flexure tumor 15 months ago. The surgical pathology was reported pT4 NO M0 mucinous adenocarcinoma with negative 42 lymph nodes. The patient received adjuvant chemotherapy for five courses. Postoperatively, carcinoembryonic antigen (CEA) levels reduced from $8.81 \mathrm{ng} / \mathrm{ml}$ to 3.78 $\mathrm{ng} / \mathrm{ml}$. However, during the follow-up period under chemotherapy, the patients' CEA level increased from 3.78 $\mathrm{ng} / \mathrm{ml}$ to $23.99 \mathrm{ng} / \mathrm{ml}$ in a 12 months course. Colonoscopy was repeated for local recurrence. No pathological features and local recurrence were observed. Abdomen magnetic resonance imaging (MRI) showed a heterogeneous mass at left seminal vesicle level, approximately $36 \times 28 \mathrm{~mm}$ in size with lobulated contours in T2-A weighted series (Figure 1a). Positron emission tomography (PET) showed increased uptake of 8Ffluorodeoxyglucose (FDG) with standardised uptake value (SUV) max of 6.5 in a compatible area with approximately $3.3 \times 2.2 \mathrm{~cm}$ dimensions between the rectum and bladder on concurrent CT. Except that, no hypermetabolic focus was detected elsewhere. Surgical excision of the metastatic mass, which was located in left seminal vesicle, was performed and the frozen section was requested perioperatively. As the primary or colon metastasis could not be differentiated by frozen section, colon resection was performed. The postoperative course was unremarkable. Partial colonic resection material had no tumor or tumor infiltration. Left vesicle was infiltrated by mucinous adenocarcinoma. Immunohistochemically, the tumor was CDX2, cytokeratin 20 (CK20), and CK7 positive (Figure 1b). Prostate-specific antigen (PSA) and thyroid transcription factor 1 (TTF-1) were negative which supported metastasis of colon carcinoma.

Seminal vesicle metastasis due to renal cell carcinoma, seminoma, malignant thymoma, hepatocellular carcinoma, and lung adenocarcinoma have been reported in the literature; more rarely, metastases to seminal vesicles and retrovesicular space have also been documented from primary carcinomas of prostate, bladder or rectum. ${ }^{3,4}$

We report an uncommon pattern of metastasis in primary colonic mucinous adenocarcinoma presenting as metastasis of left seminal vesicle without lymph node and other solid organ metastatic involvement. Since, no perforation was reported during the first operation, seeding and contamination of tumor were not considered in the pathogenesis of this isolated metastasis. Besides, the absence of any macroscopic or microscopic tumor cells in the colon resection material excluded the suspicion of tumor seeding. This case demonstrates an extremely rare pattern of metastasis of CRC. There is no known pathophysiological aetiology for such isolated metastases. Postoperative CEA levels, which may increase significantly in postoperative follow-up, should alert the clinicians for local recurrence or atypical distant metastasis at an early stage.

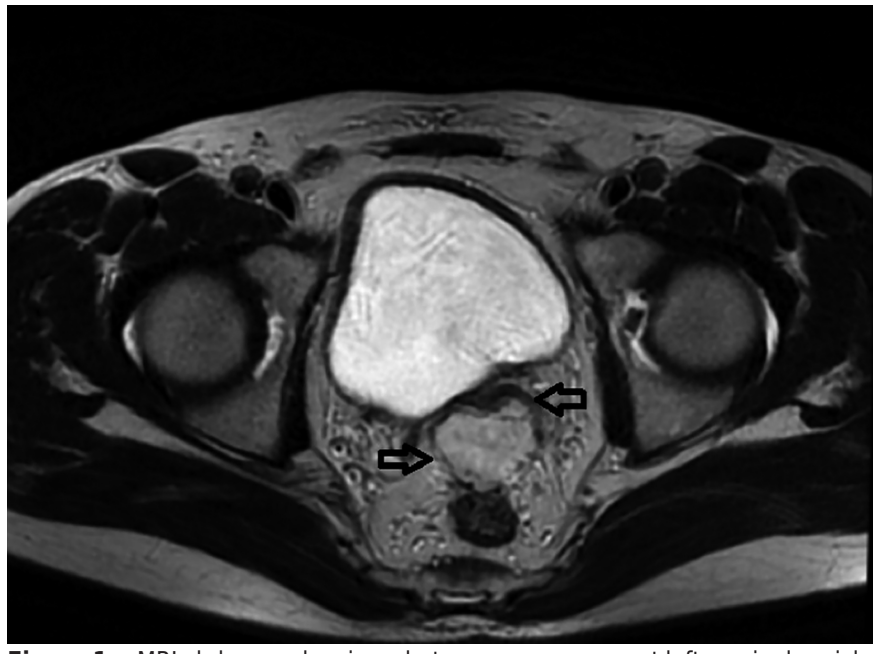

Figure 1a: MRI abdomen showing a heterogeneous mass at left seminal vesicle level, approximately $36 \times 28 \mathrm{~mm}$ withlobulated contoursinT2-Aweighted series.

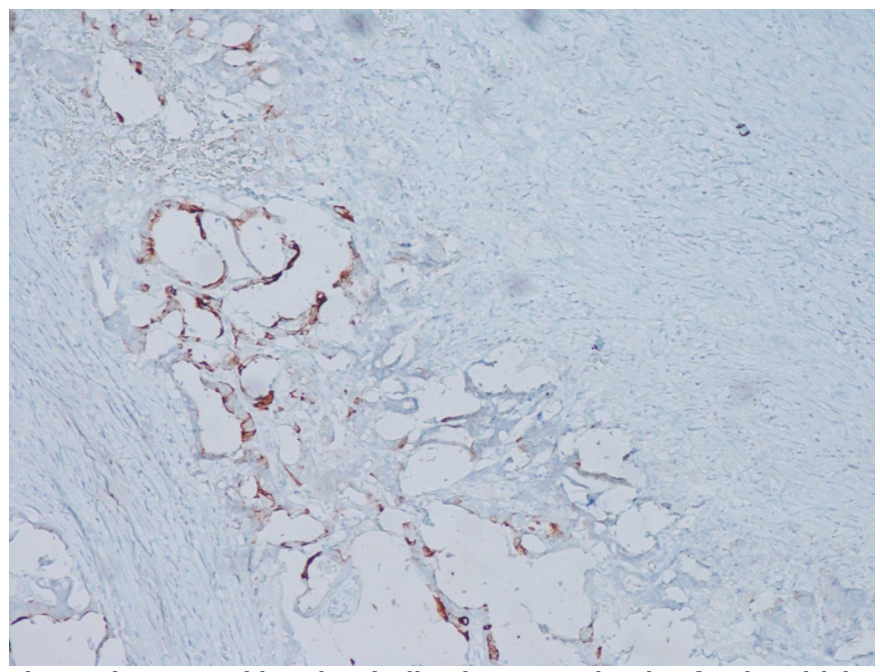

Figure 1b: Immunohistochemically, the tumor showing focal positivity (brown colour) ofcytokeratin 20 (CK20). (IHC, ×200).

\section{CONFLICT OF INTEREST:}

No conflict of interest was declared by all the authors.

\section{AUTHORS' CONTRIBUTION:}

SDA: Designed, prepared and wrote the article.

LU, SDA: Collected the patient's data, participated in surgical and medical treatment of the patient.

CA: Participated in the design and coordination of the article. All authors have read and approved the article. 


\section{REFERENCES}

1. Emile SH, Magdy A, Elnahas W, Hamdy O, Abdelnaby M, Khafagy W. Predictors for local recurrence and distant metastasis of mucinou colorectal adenocarcinoma. Surgery 2018; S0039-6060(17):30879-6. doi: 10.1016/ j.surg.2017. 11.028.

2. Belabdi D, Oukkal M, Hadjam F. A typical metastatic sites of colon cancer: Report of 4 cases. Pan Arab J Oncology 2019; 12(2).

3. Hsu YL, Lin IC, Tung CL. 18F-FDG PET/CT of seminal vesicle metastasis from ascending colon adenocarcinoma. Clin Nucl Med 2017; 42(2):138-9. doi: 10. 1097/RLU.0000000000001519.

4. Katafigiotis I, Sfoungaristos S, Duvdevani M. Primary adenocarcinoma of the seminal vesicles. A review of the literature. Archivio Italiano di Urologia e Andrologia 2016; 88(1):47-51. doi: 10.4081/aiua.2016.1.47.

Semra Demirli Atici, Levent Ugurlu and Cengiz Aydin

Department of General Surgery, University of Health Sciences, Tepecik Training and Research Hospital, Izmir, Turkey

Correspondence to: Dr. Semra Demirli Atici, Department of General Surgery, University of Health Sciences, Tepecik Training and Research Hospital, Izmir, Turkey

E-mail: smrdemirli@hotmail.com

Received: January 14, 2020; Revised: February 25, 2020; Accepted: March 09, 2020

DOI: https://doi.org/10.29271/jcpsp.2021.06.752 